\title{
Pre-Pulseless Takayasu Arteritis in a Child Represented With Prolonged Fever of Unknown Origin and Successful Management With Concomitant Mycophenolate Mofetill and Infliximab
}

\author{
Rabia Miray KIŞLA EKİNCI' ${ }^{1}$, Sibel BALCI ${ }^{1}$, Ferhat Can PISSKİN ${ }^{2}$, Celal VARAN ${ }^{3}$, \\ Sevcan ERDEM ${ }^{3}$, Mustafa YILMAZ ${ }^{1}$ (i) \\ ${ }^{1}$ Department of Pediatric Rheumatology, Çukurova University Faculty of Medicine, Adana, Turkey \\ ${ }^{2}$ Department of Radiology, Çukurova University Faculty of Medicine, Adana, Turkey \\ ${ }^{3}$ Department of Pediatric Cardiology, Çukurova University Faculty of Medicine, Adana, Turkey
}

\begin{abstract}
Takayasu arteritis (TA) is classified as a large vessel vasculitis of predominantly aorta and its main branches, resulting in fibrosis and stenosis. Only a minority of TA patients are diagnosed in pre-stenosis phase when constitutional symptoms including fever, arthralgia, weight loss, headache, abdominal pain, and elevated acute phase reactants are dominant insidious characteristics. In this article, we present a 12-year-old female patient, who was referred to our department with a one-year history of low-grade fever, fatigue, and myalgia. Physical examination did not reveal pulse and blood pressure discrepancies between any extremities. Acute phase reactants were markedly elevated, and autoantibodies were negative. Magnetic resonance angiography (MRA) findings have confirmed TA diagnosis with prominent vessel wall thickening in the ascendant and abdominal aorta, focal ectasias and a thoracoabdominal fusiform aneurysm. As methotrexate and methylprednisolone treatment during three months was unsuccessful, infliximab was induced. During the next 12 months, patient had clinical improvement, but worsening of MRA findings and new onset of carotidynia forced us to switch methotrexate to mycophenolate mofetil. Six months later, laboratory and radiological remission were achieved. In conclusion, we report a challenge to diagnose pre-pulseless childhood-TA (c-TA) in the state of prolonged fever with no signs of vascular stenosis, systemic hypertension, pulses and blood pressure discrepancies, bruits and claudication. Therefore, we wish to discourse the importance of early diagnosis of TA since, to our knowledge, there are no studies investigating treatment success only in the early phases of c-TA.

Keywords: Fever of unknown origin, infliximab, mycophenolate mofetil, pre-pulseless, Takayasu arteritis.
\end{abstract}

Takayasu arteritis (TA) is classified as a large vessel vasculitis of predominantly aorta and its main branches, characterized by granulomatous vessel wall inflammation resulting in fibrosis and stenosis. It is very rare in pediatric age with an estimated incidence of 2.6/1,000,000.1-3 The most common late-term findings are hypertension, claudication of extremities and pulselessness, stroke and aneurysm or stenosis of several arteries. ${ }^{4-7}$ Constitutional symptoms including fever, arthralgia, weight loss, headache, and abdominal pain and elevated acute phase reactants are characteristic for pre-pulseless (stenosis) TA. ${ }^{1}$ Only 33\% of TA patients are diagnosed in pre-pulseless phase, despite the advances in imaging techniques and awareness of the disease in the last decade. ${ }^{4}$ Mortality rates significantly decreased thanks to improvements in

Received: May 08, 2018 Accepted: June 21, 2019 Published online: November 06, 2019

Correspondence: Rabia Miray Kışla Ekinci, MD. Çukurova Üniversitesi Tıp Fakültesi Çocuk Romatolojisi Bilim Dalı, 01330 Sarıçam, Adana, Turkey. Tel: +90 507 - 2171190 e-mail: mir_kisla@hotmail.com 
TA management, nonetheless $57.4 \%$ of childhoodTA (c-TA) patients still undergo revascularization procedures. ${ }^{8,9}$

Fever of unknown origin (FUO) is defined as fever higher than $38.3^{\circ} \mathrm{C}$, lasting more than three weeks in a patient whose diagnosis cannot be established after one-week hospitalization. ${ }^{10}$ In this article, we present a patient with FUO with established pre-pulseless c-TA, who was successfully treated with mycophenolate mofetil (MMF), infliximab, and concomitant steroids.

\section{CASE REPORT}

A 12-year-old female patient was hospitalized in another center with a two-month history of fever, weight loss, fatigue, and generalized myalgia. She had a painful, hyperemic, firm and indurated lesion on the inner face of right thigh, which had been determined as superficial thrombophlebitis by ultrasonography and skin biopsy. The patient had been subsequently treated with systemic steroids for three months and was referred to our department since lowgrade fever, myalgia and fatigue relapsed after suspension of systemic steroids. A written informed consent was obtained from the patient and her legal guardians.
Initial physical examination was normal, including blood pressure and there were no pulse and blood pressure discrepancies among extremities. Acute phase reactants were markedly elevated and autoantibodies were all negative. Viral and bacterial serological markers, interferongamma release assay and tuberculin skin test were negative. Abdominal ultrasound, chest X-ray, skin pathergy test and ophthalmological examination were also normal. Renal Doppler ultrasonography revealed diffuse vessel wall thickening and lumen narrowing of renal arteries. Magnetic resonance angiography (MRA) led to the diagnosis of large vessel vasculitis (Figure 1a). Echocardiography also showed vessel wall thickening in the ascendant aorta. Fortunately, carotid Doppler ultrasonography did not reveal stenosis or reduced blood flow, although vessel wall thickening was present in bilateral common carotid arteries.

After TA diagnosis was established, systemic methylprednisolone $(2 \mathrm{mg} / \mathrm{kg} /$ day $)$ and methotrexate $\left(15 \mathrm{mg} / \mathrm{m}^{2}\right.$ per week) were initiated. Three months later, current therapy did not alleviate the systemic symptoms, so an anti-tumor necrosis factor-alpha agent infliximab $(7 \mathrm{mg} / \mathrm{kg})$, was added. After six months, methylprednisolone could be gradually tapered to $0.3 \mathrm{mg} / \mathrm{kg}$ per day. One year after the initiation of infliximab, carotid Doppler
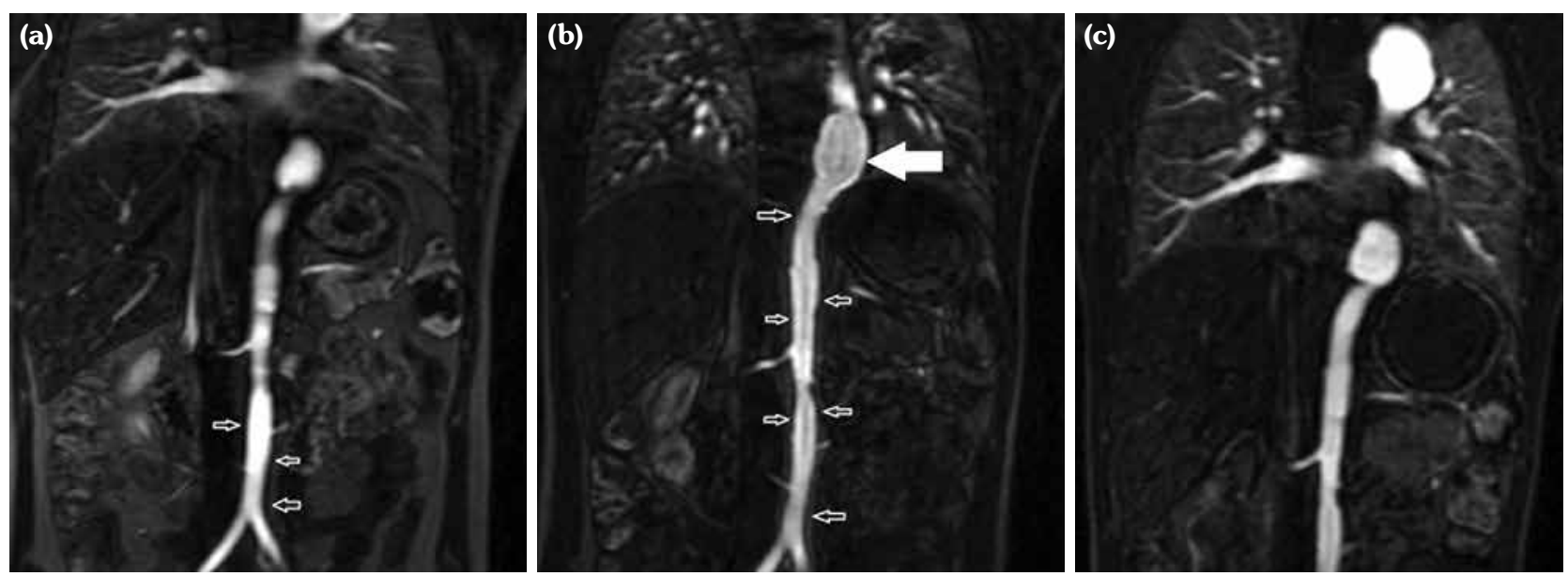

Figure 1. Magnetic resonance angiography (MRA) images confirmed diagnosis of aortitis in our patient with Takayasu arteritis and revealed changes during follow-up. (a) Initial MRA shows vessel wall thickening throughout abdominal aorta (small arrows), focal ectasias and millimetric narrowing of aorta lumen and a fusiform aneurism with a $27.8 \mathrm{~mm}$ lumen diameter at thoracoabdominal junction of aorta. (b) Enhancement of vessel wall distance (small arrows) throughout abdominal aorta is visible in MRA at $15^{\text {th }}$ month of follow-up. Large arrow also shows stable thoracoabdominal aortic junction. (c) Although focal ectasias and thoracoabdominal fusiform aneurism remain stable, abdominal aorta thickening has been completely resolved in MRA at end of follow-up. 
Table 1. Laboratory results of patient with childhood-Takayasu arteritis at diagnosis and follow-up

\begin{tabular}{lccc}
\hline Parameters & At diagnosis & $\begin{array}{c}\text { After } 12 \text { months of } \\
\text { MTX-INF-MP treatment }\end{array}$ & $\begin{array}{c}\text { After } 6 \text { months of } \\
\text { MMF-INF-MP }\end{array}$ \\
\hline Leukocytes $\left(/ \mathrm{mm}^{3}\right)$ & 17270 & 19800 & 15100 \\
Thrombocytes $\left(/ \mathrm{mm}^{3}\right)$ & 557000 & 386000 & 324000 \\
Hemoglobin $(\mathrm{gr} / \mathrm{dL})$ & 8.4 & 12.5 & 14.8 \\
ESR $\left(\mathrm{mm} / 1^{\text {st }} \mathrm{h}\right)$ & 116 & 38 & 7 \\
CRP $(\mathrm{mg} / \mathrm{dL})$ & 14.8 & 7.7 & 0.1 \\
C3 $(\mathrm{mg} / \mathrm{dL})$ & 245 & $\mathrm{Nd}$ & $\mathrm{Nd}$ \\
C4 $(\mathrm{mg} / \mathrm{dL})$ & 45.5 & $\mathrm{Nd}$ & $\mathrm{Nd}$ \\
IgG $(\mathrm{mg} / \mathrm{dL})$ & 1956 & $\mathrm{Nd}$ & $\mathrm{Nd}$ \\
IgA $(\mathrm{mg} / \mathrm{dL})$ & 384 & $\mathrm{Nd}$ & $\mathrm{Nd}$ \\
IgM $(\mathrm{mg} / \mathrm{dL})$ & 155 & $\mathrm{Nd}$ & $\mathrm{Nd}$ \\
\hline MTX: Methotrexate; INF: Infliximab; MP: Methylprednisolone; MMF: Mycophenolate mofetil; ESR: Erythrocyte sedimentation rate; CRP: C-reactive protein; \\
C: Complement component; Ig: Immunoglobulin; Nd: Not determined.
\end{tabular}

ultrasonography was repeated due to new onset of carotidynia and revealed diffuse stenosis in bilateral common carotid arteries. Furthermore, MRA showed the fusiform thoracoabdominal aneurysm and progression of abdominal aortitis (Figure 1b). We decided to switch methotrexate to MMF $\left(600 \mathrm{mg} / \mathrm{m}^{2} /\right.$ day $)$. Six months later under MMF, infliximab and low-dose of systemic methylprednisolone treatment, MRA showed complete regression of wall thickening in the abdominal aorta (Figure 1c). The laboratory results of the patient were summarized in Table 1.

\section{DISCUSSION}

Diagnosis of TA is particularly difficult in prepulseless phase due to the absence of a specific laboratory test, autoantibodies or biomarkers. ${ }^{1,2}$ Establishing an early pre-pulseless TA can be utilized by consideration of the possible prepulseless TA in patients with systemic symptoms and elevated acute phase reactants. ${ }^{11}$ Conventional angiography was previously the gold standard imaging technique in TA diagnosis, but European League Against Rheumatism (EULAR) now recommend MRA to provide information about mural thickness and contrast enhancement with luminal changes. ${ }^{12}$ For accurate diagnosis and classification of c-TA, Single Hub and Access point for pediatric Rheumatology in Europe
(SHARE) initiative favors EULAR/Paediatric Rheumatology International Trials Organisation/ Paediatric Rheumatology European Society (EULAR/PRINTO/PRES) criteria, in which the diagnosis depends on one major criteria of typical angiographic abnormalities, and at least one minor criteria, including pulse deficits, blood pressure discrepancy between any extremities, bruits, arterial hypertension and elevated acute phase reactants (erythrocyte sedimentation rate $\geq 20 \mathrm{~mm} /$ hour or C-reactive protein $\geq 6 \mathrm{mg} / \mathrm{L}$ ). ${ }^{13,14}$

Due to the difficulties to establish an accurate diagnosis of TA, particularly in pediatric cases where a significant proportion of patients do not meet the aforementioned classification criteria, diagnosis of c-TA is an important challenge in everyday clinical practice. A recent cohort, including $71 \mathrm{c}$-TA patients, emphasized this issue by declaring that $26.8 \%$ of participants had a misdiagnosis at disease onset. Majority of misdiagnoses included aortic coarctation and rheumatic fever, whereas only one patient had been diagnosed as having FUO before c-TA. ${ }^{15}$ TA has been occasionally reported in adults with FUO. ${ }^{16-18}$ Due to the rarity of cases with FUO eventually diagnosed with c-TA, we think that there is still an underestimation of early manifestations of TA.

Corticosteroid (CS) is the mainstay of TA treatment; however, a significant proportion of 
the patients do not respond to $\mathrm{CS}$ and require additional immunosuppressive drugs and biological agents. ${ }^{4,5}$ Methotrexate, cyclophosphamide, azathioprine and MMF were the most prescribed immunosuppressive agents, whereas infliximab, and tocilizumab are promising biological agents. ${ }^{3,8}$ A recent adult study suggested that MMF may be a cornerstone agent in TA treatment for better long-term outcome and safety profile. ${ }^{19}$ With this regard, since our patient did not respond to the combination therapy with methotrexate and infliximab in addition to glucocorticoids, we were forced to switch methotrexate to MMF, with complete clinical, radiological and laboratory remission.

In conclusion, this report highlights a diagnostic challenge of a child with FUO, which resulted in c-TA diagnosis during pre-pulseless phase. Besides, the patient had no signs of vascular stenosis, including systemic hypertension, discrepancy in pulses or blood pressure, bruits and claudication. We also emphasize the favorable response to concomitant MMF, infliximab and systemic methylprednisolone therapy in the early phase of the disease. Further multicenter studies including pre-pulseless patients are needed to clarify the long-term treatment outcomes of c-TA.

\section{Declaration of conflicting interests}

The authors declared no conflicts of interest with respect to the authorship and/or publication of this article.

\section{Funding}

The authors received no financial support for the research and/or authorship of this article.

\section{REFERENCES}

1. Di Santo M, Stelmaszewski EV, Villa A. Takayasu arteritis in paediatrics. Cardiol Young 2018;28:35461.

2. Kerr GS, Hallahan CW, Giordano J, Leavitt RY, Fauci AS, Rottem M, et al. Takayasu arteritis. Ann Intern Med 1994;120:919-29.

3. Aeschlimann FA, Eng SWM, Sheikh S, Laxer RM, Hebert D, Noone D, et al. Childhood Takayasu arteritis: disease course and response to therapy. Arthritis Res Ther 2017;19:255.
4. Gudbrandsson B, Molberg Ø, Palm Ø. TNF inhibitors appear to inhibit disease progression and improve outcome in Takayasu arteritis; an observational, population-based time trend study. Arthritis Res Ther 2017;19:99.

5. Keser G, Direskeneli H, Aksu K. Management of Takayasu arteritis: a systematic review. Rheumatology (Oxford) 2014;53:793-801.

6. Kim ESH, Beckman J. Takayasu arteritis: challenges in diagnosis and management. Heart 2018;104:558-65.

7. Barra L, Yang G, Pagnoux C. Non-glucocorticoid drugs for the treatment of Takayasu's arteritis: A systematic review and meta-analysis. Autoimmun Rev 2018;17:683-93.

8. Fan L, Zhang H, Cai J, Yang L, Liu B, Wei D, et al. Clinical course and prognostic factors of childhood Takayasu's arteritis: over 15-year comprehensive analysis of 101 patients. Arthritis Res Ther 2019;21:31.

9. Ohigashi H, Haraguchi G, Konishi M, Tezuka D, Kamiishi $T$, Ishihara $T$, et al. Improved prognosis of Takayasu arteritis over the past decade-comprehensive analysis of 106 patients. Circ J 2012;76:1004-11.

10. Larson EB, Featherstone HJ, Petersdorf RG. Fever of undetermined origin: diagnosis and follow-up of 105 cases, 1970-1980. Medicine (Baltimore) 1982;61:269-92.

11. Keser G, Aksu K, Direskeneli H. Takayasu arteritis: an update Turk J Med Sci 2018;48:681-97.

12. Dejaco C, Ramiro S, Duftner C, Besson FL, Bley TA, Blockmans D, et al. EULAR recommendations for the use of imaging in large vessel vasculitis in clinical practice. Ann Rheum Dis 2018;77:636-43.

13. de Graeff N, Groot N, Brogan P, Ozen S, Avcin T, Bader-Meunier B, et al. European consensus-based recommendations for the diagnosis and treatment of rare paediatric vasculitides - the SHARE initiative. Rheumatology (Oxford) 2019;58:656-671.

14. Özen S, Pistorio A, Iusan SM, Bakkaloglu A, Herlin T, Brik R. et al. EULAR/PRINTO/PRES criteria for Henoch-Schonlein purpura, childhood polyarteritis nodosa, childhood Wegener granulomatosis and childhood Takayasu arteritis: Ankara 2008. Part II: Final classification criteria. Ann Rheum Dis 2010;69:798-806.

15. Clemente G, Silva CA, Sacchetti SB, Ferriani VPL, Oliveira SK, Sztajnbok F, et al. Takayasu arteritis in childhood: misdiagnoses at disease onset and associated diseases. Rheumatol Int 2018;38:1089-94.

16. Akin E, Coen A, Momeni M. PET-CT findings in large vessel vasculitis presenting as FUO, a case report. Clin Rheumatol 2009;28:737-8.

17. Uthman IW, Bizri AR, Hajj Ali RA, Nasr FW, Khalil IM. Takayasu's arteritis presenting as fever of unknown origin: report of two cases and literature review. Semin Arthritis Rheum 1999;28:280-5. 
18. Meave A, Soto ME, Reyes PA, Cruz P, Talayero JA, Sierra C, et al. Pre-pulseless Takayasu's arteritis evaluated with 18F-FDG positron emission tomography and gadolinium-enhanced magnetic resonance angiography. Tex Heart Inst J 2007;34:466-9.

19. Goel R, Danda D, Joseph G, Ravindran R,
Kumar S, Jayaseelan V, et al. Long-term outcome of 251 patients with Takayasu arteritis on combination immunosuppressant therapy: Single centre experience from a large tertiary care teaching hospital in Southern India. Semin Arthritis Rheum 2018;47:718-726. 